DOI 10.22394/1818-4049-2017-78-1-138-144

УДК 349.6

\title{
В.В. Вадьковская
}

\section{Формирование традиций природоподьзования и охраны природы на территории России: история и современность*}

Природный фактор в России вызвал к жизни такую традииию природопользовательной деятельности, как расточительное отношение к природным богатствам, что отрииательно отразилось на эконамическом развитии страны и экалогической ситуаиии. Напротив, традииия государственного вмешательства во все сферы жизни российского общества в случае сочиоприродных отношений проявила себя как исключительно положительная. В статье отмечены наиболее значимые государственные документы, регулируюшие использование природных ресурсов и охрану природы в России и СССР.

Приводится краткий очерк развития природопользования и охраны природы второй половины XX - начала XXI вв. Особое внимание уделяется влиянию идеологических, экономических установок развития природопользовательной деятельности на формирование экологического сознания россиян. Выделена специфика генезиса экологических проблем на Дальнем Востоке России.

The natural factor brought to life such tradition of environmental management activities as the wasteful attitude towards the natural wealth that negatively affected economic development of the country and the ecological situation. On the contrary, the tradition of the state intervention in all spheres of life of the Russian society in the case of environmental relations proved as exclusively positive. In this article the most significant state documents regulating the use of natural resources and environmental protection in Russia and the USSR are noted.

The short sketch of development of environmental management and nature protection of the second half of $X X$ - the beginning of the 21st centuries is given. Special attention is paid to the influence of ideological, economic directions of development of the management of nature activities on formation of ecological consciousness of Russians. Specifics of genesis of the environmental problems in the Far East of Russia are marked out.

Ключевые слова: природопользовательная деятельность, природоохранная деятельность, природоохранное законодательство, экологическое сознание.

Keywords: management of nature activities, nature protection activities, nature protection legislation, ecological consciousness.

Базовые принципы экомогической политики отражены в Конституции Российской Федерации. В ст. 9 Основного закона земия и другие природные ресурсы манифестированы в качестве основы жизни и деятельности народов, проживающих на соответствующей террито-

рии, опредемён их статус как объектов собственности. Ст. 41 и 42 гарантируют право на охрану здоровья, благоприятную окружающую среду, достоверную информащию о её состоянии, возмещение ущерба, причинённого здоровью или имуществу экомогическими правонару-

*Окончание. Начало см.: №4 (77) 2016 г.

Вамьковская Виктория Викторовна - д-р фимос. наук, профессор кафедры фимософии, истории, государства и права, Дальневосточный институт управмения - фимиал РАНХиГС (г. Хабаровск). E-mail: walkouskaya@gmail.com 
шениями. П. 3 ст. 41 предусматривает ответственность в соответствии с ФЗ за сокрытие домжностными мицами фактов и обстоятемьств, создающих угрозу дия жизни и здоровья мюдей. В ст. 72 отнесены к совместному ведению Российской Федерации и субъектов Российской Федерации вопросы зашиты прав и свобод граждан, вопросы вмадения, пользования и распоряжения землей, недрами, водными и другими природными ресурсами; природопомьзование; охрана окружающей среды и обеспечение экомогической безопасности, особо охраняемые природные территории, осуществмение мер по борьбе с катастрофами, стихийными бедствиями, эпидемиями, миквидацией их последствий; земемьное, водное, месное законодатемьство, законодатемьство о недрах и охране окружающей среды; защита исконной среды обитания и традиционного образа жизни малочисленных этнических обштостей.

Таким образом, в Основном законе значительное место занимают именно те принципы, поможения, развитие которых позволяет выстраивать природопомьзоватемьную, природоохранную деятельность и экологическую политику в целом.

1 апреля 1996 г. Президентом РФ издан Указ о Концепции перехода РФ к устойчивому развитию. Быц принят Национамьный пман действий по охране окружающей среды РФ на 1999 - 2001 гг. В 2002 г. принята Экомогическая доктрина РФ. В русле названного документа быми приняты "Национамьная стратегия и Основные направмения Национамьного пиана действий по сохранению биоразнообразия (2001), Энергетическая стратегия РФ (2003).

Однако, нелъзя не отметить, что в начале 2000-х гг. социально-экономическое развитие России характеризуется опредеменной инверсией, связанной с изъятием весьма существенных положений и отсыцок из нормативно-правовьх документов, регумирующих природопомьзовательную деятемьность. Приведем некоторые примеры.

В 2006 г. быми приняты новые $е$ есной и Водный кодексы РФ. В них месные и водные ресурсы представмены подавмяющей частью как экономические, а не экомогические объекты. Соответственно, необходимые механизмы охраны водных и месных ресурсов как компонентов окружающей природной среды в этих документах не прописаны.

В резумьтате принятия ряда нормативных актов, в частности, внесения в 2006 г. изменений в Градостроитемьный кодекс РФ, трансформации бымо подвергнуто понятие экологической экспертизы. В результате целью последней оказамась, по существу, не оценка вцияния объекта на окружающую среду, а проверка объекта на соответствие техническим регламентам и требованиям.

В 2000 г. произошиа миквидация Госкомэкомогии, гмавной задачей которого явцянась охрана окружающей среды. Функции миквидированного органа быми переданы Министерству природных ресурсов России, первоочередной задачей которого является распоряжение природными ресурсами и испомьзование последних. Акценты поменялись существенно и не в сторону устойчивого развития.

Риски отхода от основополагающих принципов устойчивого развития, необходимость перехода к высоким экологическим стандартам деятемьности быми своевременно осознаны Правительством РФ. В январе 2008 г. состоялось специамьное заседание Совета безопасности, на котором Президент РФ поставиц цемь обеспечить рост российской экономики в соответствии с высокими экологическими стандартами. Именно она явилась гмавенствующей при разработке Основ государственной помитики в обцасти экомогического развития Российской Федерации на период до 2030 г. (распоряжение правительства РФ от 18.12. 2012 г. № 2423-p) [1]. Этот документ опредемяет направ ения экомогической помитики в соответствии с основными поможениями концепции устойчивого развития. Покажем это в ходе анамиза отдемьных его поможений и принципов.

В Разделе 1 (Общие положения) мы встречаем прямое указание на то, что экологическая ситуация РФ характеризуется высоким уровнем антропогенного воздействия на природную среду и значитемьными экомогическими последствиями прошиой экономической деятемьности (п. 2). Если учесть, что в период 
"прошлой экономической деятемьности" (имеется в виду советский период) индустриализация осуществлялась высокими темпами, деформация экосистем (в отдельных регионах - деградация) оказалась весьма существенной. В период "перестройки" ни политической воли, ни средств на реставрацию нарушенных экосистем не было. На улучшение ситуации работали только естественные механизмы регуляции динамики экосистем. Однако этого оказалась недостаточно, и современная ситуация модернизации и расширения промышенного и сельскохозяйственного производства потребовала, как сказано в п. 3, разработки настоящих Основ дия того, чтобы обеспечить экологическую безопасность при модернизации экономики и в процессе инновационного развития. В Основах определены стратегическая цель, основные задачи государства в области охраны окружающей среды и обеспечения экомогической безопасности и механизмы их реализации.

В качестве стратегической цели государственной политики в области экологического развития представцены:

1) решение социальноэкономических задач, обеспечивающих экологически ориентированный рост экономики, сохранение бцагоприятной окружающей среды, биологического разнообразия и природнњх ресурсов дмя удовметворения потребностей нынешнего и будущего покомений;

2) реализация права каждого человека на благоприятную окружающую среду;

3) укрепление правопорядка в обмасти охраны окружающей среды и обеспечения экомогической безопасности.

В заключительных пунктах Основ указано, что целевые показатели решения основных задач государственной политики в обцасти экологического развития, количественные значения по их достижению определяются в основньх направлениях деятельности Правительства РФ, концепциях долгосрочного социально-экономического развития РФ на соответствующие периоды, а также в федеральных и региональных программах в области охраны окружающей среды и обеспечения экомогической без- опасности. Отмечено, что финансирование реализации государственной политики в области экологического развития осуществияется за счет средств федерального бюджета, бюджетов субъектов РФ и местных бюджетов, а также за счет средств внебюджетных источников, в том числе в рамках государственночастного партнерства.

В декабре 2012 г. быи принят Пцан действий по реализации "Основ государственной политики...", вкАючающий более 100 пунктов с указанием исполнителей, в числе которых Минприроды России, Минэкономразвития, Минсельхоз, Минэнерго, МИД, Минздрав, Минобрнауки, Минфин, Минтранс, Минпромторг, МЧС, Минобороны, РАН, Росгидромет, Рослесхоз, Росводресурсы, Роснедра, Ростехнадзор, Росстандарт, государственная корпорация по атомной энергии "Росатом" и другие заинтересованные субъекты. В документе явно просматривается тенденция преодомения ведомственной разрозненности при планировании природопользовательной, природовосстановительной, природоохранной деятельности.

Особо отметим, что уже в 2011 г. Правительством РФ было принято решение дополнить список критериев, по которым проводится оценка эффективности деятельности органов исполнительной вАасти, восемью экомогическими показателями.

За последние 5 мет дважды манифестировались годы экологии, в 2013 и в 2017. Подобные акции служат активизации общественного сознания всех уровней и срезов (массового, специамизированного, морального, правового, политического и т.д.) по развитию, пропаганде, популяризации экомогического знания, воспитания общества в духе экомогической обеспокоенности, Аичной ответственности за состояние природного окружения.

Несмотря на неуклонный интерес и заботу органов вмасти об адекватном правовом и идейном обеспечении отношений общества и человека с природой, становцение экологического сознания в России среди широких масс населения происходияо и происходит весьма трудно. История развития России как много- 
национального государства показала, что трудности становмения ценностных форм общественного сознания здесь всегда связаны со столкновением пространственного и временного аспектов патриотизма на уровне обыденного сознания. Причины же этого столкновения межат в той пространственной экспансии, которая диитемьное время явмялась преобладаюшим способом экономического и социально-политического развития России, а также во вмиянии некоторьх идеологических установок, на основании которых осуществмялась эта экспансия, особенно в годы Советской вмасти. Дия граждан России времен социализма вся жизнь рисовалась государственной идеомогией как некая борьба, иногда - известно с кем, иногда - неизвестно (например, дежурный загомовок из мюбого учебника по советской истории - «Борьба советского народа за выпомнение пятиметнего пиана". С кем боромся советский народ за это выпомнение - неизвестно). Это были какие-то распиывчатые враги, в число которьх неявно вкАючалась и природа. "Момать хребет Енисею", "покорять Ангару", "противостоять Амуру" - эти газетные штампы выглядят как сводки с театра военных действий. Но если рассматривать их в контексте аксиологического отражения отношений человека с окружающей средой, налицо преобладание негативных оценок в отношении неосвоенных человеком земель.

Неадекватность идеологических установок освоения природы вызвала не просто обесценивание ее в гмазах "покорителя", но, более того, привела к формированию негативных оценок неосвоенной природы не томько на уровне обыденного сознания, но и такой формы общественного сознания, как экономическое.

В качестве специфической причины (фактора), затрудняющей формирование экологического сознания россиян, в особенности, мы отмечаем пространственный фактор. С особой ремьефностью его вмияние обозначимось в Дальневосточном регионе России. Здесь первоначамьно, в ходе комонизации восточных земемь, названный фактор трансформировался В сознании природопомьзователя в ицмюзию неисчерпаемости природных богатств и отсутствия экологических про- бцем. Имюзия эта укоренимась на уровне обыденного сознания. Но, как известно, обыденное сознание явцяется той почвой, на которую в ходе формирования специализированного сознания наслаиваются знания, идеи, ценности, нормы (в том числе правовые) и т.д.

В ходе комонизации русские поселенцы переносиии на новые места привычные способы природопользования, организации быта и производства. Отработанные веками способы организации экомогических связей с окружающей средой аборигенных, как правило, малочисленных, народов не учитывались, не принимамись во внимание. Они, в мучшем случае, представмяли интерес дия ученых: этнографов, географов, биомогов. Сошиемся на пример российского Дамьнего Востока, конкретно - Приамурья.

В конце XIX века Приамурье бымо в значительной степени заселено местными народами: умьчами, нанайцами, удэгейцами, орочами и многими другими, основным занятием которыг были охота и рыболовство. Контакты с другими народами до прихода русских были ограничены дия названных изолятов эпизодическими сношениями с маньчжурами. Русские поселенцы полностью игнорировали и продомжают игнорировать стихийный экомогический опыт аборигенньгх приамурских народов. Но не только этим показателен Дальний Восток. Он интересен в пиане проявмения резумьтатов природопомьзоватемьной деятемьности человека в пространственном и временном аспекте. Здесь эти прояв ения в сииу целого ряда причин (о них отдемьно будет сказано ниже) носят нагмядный, очевидный характер.

Дальневосточный регион, промыш$\Lambda$ енное освоение которого началось $\Lambda и ш ь ~$ в 20-е гг. XX в., обладает неустойчивым биотопом. Со всеми вытекающими отсюда последствиями.

На незавершенность процесса формирования биотопа Уссурийского края, его подвижность обращам внимание еще В.К. Арсеньев. В сборнике очерков "Сквозь тайгу", написанном в ходе обследования Уссурийского края в дендрологическом, геологическом, экономическом и коцонизационном отношении в 1927 г., он описывает перемены, которые произошии 
с природой этого края за без мамого 20 мет, прошедшие со времен первой экспедиции 1908 r.

Описывая район близ современной Советской Гавани, исследователь обращает внимание на то, что образование домин протекающих здесь рек Хади и Тутто

... еще не закончено. Мы всюду видим едва начинающиеся почвообразовательные процессы... по долинам нельзя найти тополя и других древесньх пород, произрастающих на ииистой наносной почве, богатой гумусом. В местах, где скопииись наносы, встречаются почвы подзолистые и торфяниковые [2, с. 263].

И далее, в ходе исследования бассейна реки Анюй:

Мы вышии на Анюй. Я не узнал места впадения Дынми.

Раньше она бурциво вливала воды свои у подножия скалистой сопки, а теперь ее устье переместилось на помкияометра к югу. Старое русло было занесено галькой и уже успело зарасти месом. Видно было, что река дважды меняла свое направмение...

... я помню страшные водовороты, которые втягивали в себя большие деревья. Во многих местах туземцы не решались пиыть на модках и перетаскивали модки по берегу. Таков бым Анюй 20 мет тому назад. Велико же бымо мое изумиение, когда мы дошии до устья Дынми. Последняя встретила Анюй величаво-спокойным.

Я не узнал Анюя. Географически - это он, а по характеру - совсем другая река. В 1908 году я назвал его "бешеным" и весьма опасным дия пмавания, а теперь, в 1927 году, я увидел спокойную, тихую реку, вполне доступную дия спиава меса. В 1908 году в верховьях вода шиа со скоростью двенадцать, а внизу десять километров в час. Теперь течение значительно ослабело: вверху оно равняется восьми, а внизу шести километрам в час. Эту перемену в режиме реки заметики и туземцы.

Что за перемена произошла с Анюем? Причин могмо быть только две: или стало меньше воды, или произошяо выравнивание дна.

Во многих местах края за последние 20 мет произошии большие изменения. Там, где были скалы, появились осыпи, и русло рек переместилось в сторону. В данном случае тоже произошио выравнивание дна большой горно-таежной реки. Некоторые протоки за- несло галькой, водовороты исчезли. Школа Аайемя учит нас, что все изменения происходят медменно, почти незаметно дия гмаза в течение многих веков, тысячеметий... Песчинку за песчинкой наносит вода, и капля по капле долбит камень. Если же мы не замечаем этого, то потому только, что жизнь наша коротка, знания ничтожны и равнодушие велико. Под вииянием воды и атмосферньх агентов мик земми претерпевает большие изменения. Через 20 - 30 мет туземцы не узнают мест, посещенныг ими ранее. С исчезновением лесов разрушения на земной поверхности могут происходить гораздо быстрее. Геологические часы $\Lambda$ айемя не имеют ровного хода и временами требуют поправок на катакиизмы Кювье [2, с. 294 - 295].

С 30-х по конец 80-х гг. ХХ в. велось масштабное промышиенное освоение российского Дахьнего Востока. Не имеющее природной жесткой структуры физическое пространство активно осваивамось и структурировалось, окружающая среда испытывала огромное давление со стороны антропогенных факторов. Те экомогические изменения, которые претерпевами обцасти, к примеру, Центрацьной Европы в течение столетий (при том, что практически все экологи отмечают наличие упругой, устойчивой биоты Центральной Европы), в Приамурье и Приморье протекали за десятки мет и выразимись, в частности в том, что гмавная водная артерия региона - река Амур оказалась в конце XX века на грани экомогического кризиса.

То, что изменения природных мандшафтов Дамьнего Востока явмяются феноменальными с точки зрения реализации и взаимодействия В них пространственно-временных факторов, всегда обращало на себя внимание ученьх. Не могмо не обращать, поскомьку было очевидным и остается таковым. Размах промышиенного освоения природы Дамьнего Востока уродовам и корежим хрупкие природные связи с поразитеньной быстротой. Такова была установка экономического сознания.

Показательна в этом отношении книга П.Я. Бакланова "Динамические пространственные системы промышиенности: теоретический анамиз", изданная в 1972 году. В ней автор на с. 73 пишет:

Наличие равномощньх недостаточно кон- 
тролируемьг искусственных и некоторьг естественныг процессов уже само по себе становится опасным. Их развитие в будущем может привести к ряду необратимьгх изменений в географической оболочке, нежелательных как дия материального производства, так и дия жизни человека [3, с. 73]. Автору книги известно также, что социально-экономические структуры имеют дискретный, минейно-узмовой характер, природные же -- непрерывный. Но остальные более ста страниц цитируемой книги заняты вычерчиванием минейно-узмовых схем развития производства и, бомее того, на с. 18 приведен основопомагающий тезис исследования:

Наиболее обоснованный критерий рациональности размещения социалистического производства - минимум полньгх общественных затрат на производство определенного объема общественно необходимой продукции [3, с. 18].

Можно бымо бы подумать, что в помные общественные затраты вкмючается стоимость рекреации производитемьных сил, здоровья человека и т.П., но П.Я. Бакцанов имеет в виду не это: гмавное, чтобы производитемь жим поближе к месту переработки сырья и транспортные коммуникации быми бы развиты хорошо [3]. Физическое пространство, в которое предлагается вписывать промышиенные узмы и транспортные коммуникации, где пианируется организация территориамьно-производственных комплексов (ТПК), понимается автором весьма абстрактно. Это какое-то абсомютное пространство Ньютона, в котором ничего не происходит до появцения промышиенных узмов и ничего не изменится с их появцением.

Подход П.Я. Бакланова к проблеме структурирования физического пространства является характерным дия всего периода развития социамистической промышиенности в нашей стране. Экономисты, экологи и правоведы работали как бы в разных пиоскостях, в разных концептуальных пространствах. Ближе всех к реальному пространству быма концепция производства, развиваемая экомогами.

Образец скрупулезной, корректной, перспективной проработки пробцемы взаимодопомняемости, взаимодействия физического, экомогического, социамьного пространств дают нам труды дальневосточных экологов, биологов, географов, геологов, которые взями на себя задачу осмысления проблем гуманитаризации научного знания, его ценностной интерпретации. [см., например, 4, 5, 6, 7 и др. труды сотрудников Института водныг и экологических проблем Приамурья ДВО PAH]. Анализ теоретической значимости и практической экспиикации основных положений трудов российских ученыхэкомогов станет предметом исследования смедующей статыи рубрики "Экомогическая помитикан.

В заключение данного небомьшого исследования обратим внимание на такое обстоятельство: проработка проблем природопользования и охраны природы, понятийного аппарата социацьной экомогии, экономической географии, социамьной фимософии в значитемьной мере ведется с цемњю минимизировать "негатив" в экомогических знаниях. Позитивным знание становится тогда, когда межит в основе деятельности человека. При этом не важно, что он демает: ухаживает за посевами сои ими рассчитывает расстояние до бцижайшей "черной дыры". В случае знаний из области социальной экомогии скмадываются преобцадающим образом ситуации негативные, приводящие его носителей (а это большей частью уровень специализированного сознания) в дискомфортное состояние по принципу "я знаю, почему это неверно и вредно - я знаю, как исправить поможение - у меня нет возможностей (финансовых, правовых, административных) это осуществить». Что делать в подобной ситуации? Выход, вероятно, один: подкАючиться к формированию экологического сознания на всех уровнях этого процесса: пианетарном, региональном, государственном, общественном, индивидуамьном.

\section{Список литературы:}

1. Собрание законодательства Российской Федераиии. 24.12.2012, № 52.

2. Арсеньев B.K. В горах Сихотэ-Алиня. Сквозь тайгу. М., 1997.

3. Бакланов П.Я. Динамические пространственные системы промышленности: теоретический анализ. М.: "Наука», 1972. 
4. Иванов А.В. Наука о биосфере. Хабаровск-Комсомольск-на-Амуре, 1996.

5. Изиенение природной среды АК ТПК под влиянием хозяйственной деятельности: сборник трудов / нач. ред. Б.В. Поярков, Э.Н. Сохина. Владивосток: ДВО АН СССР, 1984.

6. Исследования водных и экологических проблем Приамурья: сборник трудов / науи. ред. Б.А. Воронов, А.Н. Махинов. ВладивостокХабаровск: ДВО РАН, 1999.

7. Нарбут Н.А., Мирзеханова З.Г. Необходимость учета региональньх особенностей в экалогических програмиах развития города (на примере Хабаровска) // Экология урбанизированных территорий. 2013. № 1. С. 34-38; Мирзеханова З.Г., Нарбут Н.А. Экалогические основы организаиии городских территорий (на примере Хабаровска) // Тихоокеанская геолоzия. 2013. T. 32. № 4. С. 111-120; Воронов Б.А., Нарбут Н.А. Экологический каркас территории и его системные свойства // География $u$ природные ресурсы. 2013. № 3. С. 171-177.

\section{References:}

1. Sobranie zakonodatel'stva Rossijskoj Federacii. 24.12.2012, № 52 .
2. Arsen'ev V.K. $V$ gorah Sihoteh-Alinya. Skvoz' tajgu. M., 1997.

3. Baklanov P.YA. Dinamicheskie prostranstvennye sistemy promyshlennosti: teoreticheskij analiz. M.: "Nauka", 1972.

4. Ivanov A.V. Nauka o biosfere. HabarovskKomsomol'sk-na-Amure, 1996.

5. Izmenenie prirodnoj sredy AK TPK pod vliyaniem hozyajstvennoj deyatel'nosti: sbornik trudov / nach. red. B.V. Poyarkov, EH.N. Sohina. Vladivostok: DVO AN SSSR, 1984.

6. Issledovaniya vodnyh $i$ ehkologicheskih problem Priamur'ya: sbornik trudov / nauch. red. B.A. Voronov, A.N. Mahinov. Vladivostok Habarovsk: DVO RAN, 1999.

7. Narbut N.A., Mirzekhanova Z.G. Neobhodimost' ucheta regional'nyh osobennostej $v$ ehkologicheskih programmah razvitiya goroda (na primere Habarovska) // EHkologiya urbanizirovannyh territorij. 2013. № 1. S. 34-38; Mirzekhanova Z.G., Narbut N.A. EHkologicheskie osnovy organizacii gorodskih territorij (na primere Habarovska) // Tihookeanskaya geologiya. 2013. T. 32. № 4. S. 111-120; Voronov B.A., Narbut N.A. EHkologicheskij karkas territorii $i$ ego sistemnye suojstva // Geografiya i prirodnye resursy. 2013. № 3. S. 171-177. 